Проблеми математичного моделювання та теорії диференціальних рівнянь

УДК $532.5+\mathbf{5 2 3 . 9}$

\title{
РЕЗОНАНСИ В ДИНАМІЧНІЙ СИСТЕМІ НА ТОРАХ ПЛАНЕТАРНОГО ВИХОРУ
}

\author{
М. М. Осипчук*, В. I. Перехрест** \\ * Дніпропетровсъкий національний університет ім. Олеся Гончара, \\ Дніпропетровсък 49050. E-mail: Nykolay1111@bigmir.net \\ ** Дніпропетровсъкий начіональний університет ім. Олеся Гончара, \\ Дніпропетровсък 49050. E-mail: babaj40@mail.ru
}

Досліджується задача про існування резонансів між коловим, меридіональним та азимутальним рухами частинок течії на тороїдних поверхнях у планетарному просторовому вихорі. Запропоновано чисельно-аналітичний метод виділення резонансних траєкторій руху за початковими умовами та параметрами задачі.

Ключові слова. Планетарний вихор, резонансні умови і траєкторії, утворення супутників планет.

\section{1. Вступ}

У попередніх працях авторів $[1,2,3]$ були досліджені деякі основні властивості планетарного вихору - окремого розв'язку гідродинамічних рівнянь Ейлера для сферичних вихороутворень. Зокрема, описано загальну структуру цієї вихрової течії, що складається з кількох $(n)$ внутрішніх тороїдних вихорів та низки $(m)$ зовнішніх вихрових кілець, які обтікаються незамкнутими лініями течії та обертаються у один бік (рис.1). При цьому внутрішні вихори містяться всередині замкнутих непроникних сфер та в кульових шарах між ними, і обертання в сусідніх вихорах є протилежними за напрямом. Проведено класифікацію структур $(n, m)$ планетарних вихорів залежно від основного параметра вихору $\alpha$, який, у свою чергу, визначається трьома фізичними параметрами задачі. Порівняння теоретичних значень основних параметрів планетарного вихору з параметрами Сонячної системи виявили високий ступінь адекватності вихрової моделі реальним процесам утворення планетарних систем, зокрема подолано кардинальні суперечності більшості попередніх гіпотез (Канта, Лапласа, Джинса, Ольбертса) з реальними властивостями Сонячної системи.

У планетодинаміці є поширеними ідеї про резонансність рухів планет і супутників, ці ідеї підкріплені й численними дослідженнями $[7,8,9]$. Тому, маючи такий об'єкт як планетарний вихор, ми ставимо задачу про наявність резонансних траєкторій руху частинок у ньому.

Нижче досліджуються рух і траєкторії частинок у окремих тороїдних вихорах на основі системи диференціальних рівнянь відомого поля швидкостей.

(c) М. М. Осипчук, В. I. Перехрест, 2010 
Ця динамічна система 3-го порядку є автономною за часом та за коловою координатою і має один аналітичний перший інтеграл, проте не допускає інтегрування у замкнутому вигляді. Тому система рівнянь інтегрується чисельно з варіюванням початкового радіуса у межах даного тора та будуються траєкторії відхилення руху на торах від періодичного колового руху точок центрального кола вихору. Особливу увагу приділено встановленню резонансних режимів між коловим, меридіональним та радіальним рухами, які можуть бути важливим чинником у проблемі формування супутників планет.

\section{2. Геометрія та рух торових кілець}

У роботі [1] було отримано новий окремий розв'язок гідродинамічних рівнянь Ейлера для осесиметричних сферичних течій, який потім [2] було названо планетарним вихором. Методика інтегрування повної нелінійної системи рівнянь полягає у введенні, як звичайно [4], функції течії $\Psi(y, \theta)$, побудові спеціальних форм подання визначальних функцій та, зрештою, відокремлення змінних. Таким чином побудована функція течії у сферичних координатах $(r, \theta, \varphi)$ :

$$
\Psi=C_{2} \Phi(y) \sin ^{2} \theta, \quad \Phi(y)=\left[\alpha y^{2}+\left(\cos y-\frac{\sin y}{y}\right)\right],
$$

через яку поле швидкостей визначається формулами [4]:

$$
V_{r}=-\left(r^{2} \sin \theta\right)^{-1} \frac{\partial \Psi}{\partial \theta}, \quad V_{\theta}=(r \sin \theta)^{-1} \frac{\partial \Psi}{\partial r}, \quad \mathrm{~V}_{\varphi}=\frac{C_{0} \Psi}{r \sin \theta}
$$

У розгорнутому вигляді за формулами (2.1), (2.2) маємо поле швидкостей:

$$
\begin{aligned}
& V_{r}=-2 C_{2} C_{0}^{2}\left(\alpha+\frac{1}{y^{2}}\left(\cos y-\frac{\sin y}{y}\right)\right) \cos \theta \\
& V_{\theta}=C_{2} C_{0}^{2}\left(2 \alpha-\frac{\sin y}{y}-\frac{1}{y^{2}}\left(\cos y-\frac{\sin y}{y}\right)\right) \sin \theta \\
& V_{\varphi}=C_{2} C_{0}^{2} y\left(\alpha+\frac{1}{y^{2}}\left(\cos y-\frac{\sin y}{y}\right)\right) \sin \theta .
\end{aligned}
$$

Вище введено безрозмірний радіус $y=C_{0} r$ і параметр $\alpha$, який зрештою визначається [2] через основні параметри течії таким чином:

$$
\alpha=-\frac{V_{\infty}}{2 C_{0}^{2} C_{2}}
$$

де $V_{\infty}$ - поступальна швидкість закрученого простору, $C_{2}$ - довільна стала у розв'язку (2.1); $C_{0}$ - параметр закручування простору, що випливає з формули (2.2) для $V_{\varphi}$. Геометричні параметри кожного торового кільця планетарного вихору визначаються крайніми радіусами $y_{1}$ та $y_{2}$, радіусом центрального кола $y *$ та граничними кутами розхилу $\theta^{*}, \pi-\theta^{*}$ (рис.1). 


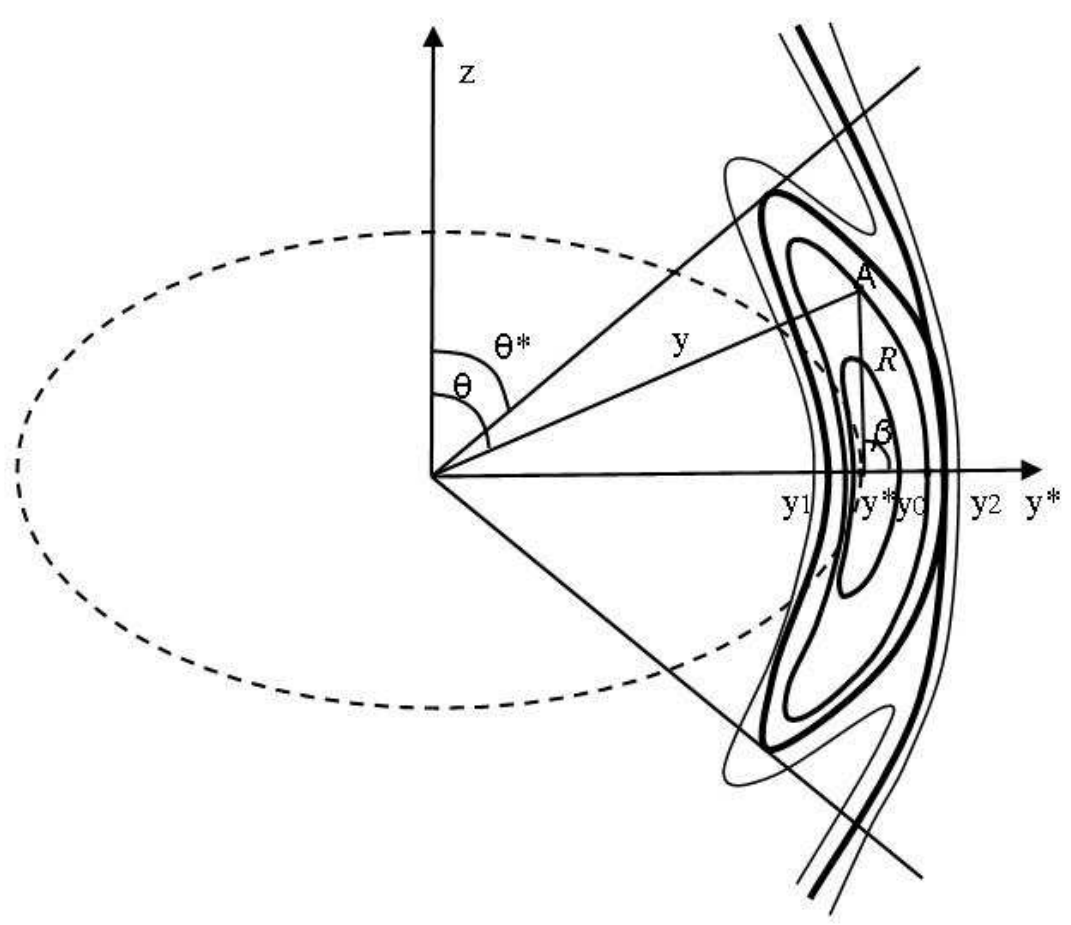

Рис. 1. Зовнішній тороїдний вихор

Методика визначення цих геометричних параметрів вихрових кілець-торів була розроблена у [3], і там наведені ці параметри для структури $(2,11)$, якою в деякому наближенні можна моделювати нашу Сонячну систему (табл. 1). Перепишемо вирази (2.3) для поля швидкостей у вигляді нормальної системи диференціальних рівнянь руху 3 -го порядку:

$$
\begin{aligned}
& \frac{d y}{d t}=-2 C_{2} C_{0}^{3}\left(\alpha+\frac{1}{y^{2}}\left(\cos y-\frac{\sin y}{y}\right)\right) \cos \theta \\
& \frac{d \theta}{d t}=\frac{C_{2} C_{0}^{3}}{y}\left(2 \alpha-\frac{\sin y}{y}-\frac{1}{y^{2}}\left(\cos y-\frac{\sin y}{y}\right)\right) \sin \theta \\
& \frac{d \varphi}{d t}=C_{2} C_{0}^{3}\left(\alpha+\frac{1}{y^{2}}\left(\cos y-\frac{\sin y}{y}\right)\right) .
\end{aligned}
$$

Динамічна система (2.5) є автономною за часом та за коловою координатою $\varphi$ і має один перший інтеграл виду $\Psi(y, \theta)=C$ або

$$
\Phi(y) \sin ^{2} \theta=C .
$$

Будемо розглядати систему (2.5) в області зовнішнього тора $\Omega$ (рис.1):

$$
y_{1} \leq y \leq y_{2} ; \theta^{*} \leq \theta \leq \pi-\theta^{*} ; 0 \leq \varphi \leq 2 \pi .
$$

Інтеграл (2.6) при варіюванні початкових точок $\left(y_{0}, \pi / 2\right) \in \Omega$ на горизонтальній осі також дає рівняння торових поверхонь, вкладених у тор $\Omega$ (рис. 2 ), причому кожна така поверхня визначається з $(2.6)$ при $C=\Phi\left(y_{0}\right)$. Введемо 
безрозмірний час $\tau=\omega^{*} t$, де $\omega^{*}$ - кутова швидкість руху по центральному колу тора. Тоді перепишемо систему рівнянь (2.5) в остаточному вигляді

$$
\begin{aligned}
& \frac{d y}{d \tau}=-2 B\left(\alpha+\frac{1}{y^{2}}\left(\cos y-\frac{\sin y}{y}\right)\right) \cos \theta \\
& \frac{d \theta}{d \tau}=\frac{B}{y}\left(2 \alpha-\frac{\sin y}{y}-\frac{1}{y^{2}}\left(\cos y-\frac{\sin y}{y}\right)\right) \sin \theta \\
& \frac{d \varphi}{d \tau}=B\left(\alpha+\frac{1}{y^{2}}\left(\cos y-\frac{\sin y}{y}\right)\right)
\end{aligned}
$$

де $B=C_{2} C_{0}^{3} / \omega^{*}$. Якщо визначити кутову швидкість $\omega^{*}$ з $(2.3)$ як $\omega^{*}=V_{\varphi}\left(y^{*}, \pi / 2\right) / r^{*}$, то

$$
B^{*}=\frac{y *^{2}}{\Phi\left(y^{*}\right)},
$$

і цей параметр у рівняннях (2.7) визначається для кожного тора окремо. Неважко бачити (рис. 2), що безрозмірна змінна інтегрування $\tau$ є полярним кутом, який слідує за рівномірним обертанням центра тора $y^{*} 3$ кутовою швидкістю $\omega^{*}$.

Таблиця 1. Параметри торових кілець планетарного вихору $(2,11)$

\begin{tabular}{|c|c|c|c|c|}
\hline № вихора & $y_{1}$ & $y^{*}$ & $y_{2}$ & $\theta^{*}$ рад. \\
\hline $\mathbf{1}$ & 0 & 2,79026114 & 4.638224959 & 0 \\
\hline $\mathbf{2}$ & 4.638224959 & 6,03419312 & 7.359705130 & 0 \\
\hline $\mathbf{3}$ & 7,36416294 & 9,44279805 & 12,32219138 & 0,05378797 \\
\hline $\mathbf{4}$ & 14,05479202 & 15,85435860 & 18,54971972 & 0,77368502 \\
\hline $\mathbf{5}$ & 20,65132327 & 22,24209605 & 24,76167868 & 1,02574913 \\
\hline $\mathbf{6}$ & 27,20957617 & 28,62398544 & 30,96568847 & 1,17671320 \\
\hline $\mathbf{7}$ & 33,74923231 & 35,00553545 & 37,16351818 & 1,27803419 \\
\hline $\mathbf{8}$ & 40,28122905 & 41,38978337 & 43,35502601 & 1,35112878 \\
\hline $\mathbf{9}$ & 46,81397240 & 47,77942842 & 49,53890086 & 1,40681551 \\
\hline $\mathbf{1 0}$ & 53,35626851 & 54,17790040 & 55,71246457 & 1,45123869 \\
\hline $\mathbf{1 1}$ & 59,92070050 & 60,59086484 & 61,87049552 & 1,48829250 \\
\hline $\mathbf{1 2}$ & 66,53253005 & 67,03060790 & 68,00098738 & 1,52092619 \\
\hline $\mathbf{1 3}$ & 73,28303744 & 73,54281412 & 74,05844130 & 1,55296938 \\
\hline
\end{tabular}

Система рівнянь (2.7) інтегрується чисельно в пакетах Maple методом Рунге-Кутта-Фельберга на проміжках $0 \leq \tau \leq 2 \pi n,(n=1,2, \ldots)$, при цьому початкові точки $y_{0}$ бралися на горизонтальній осі з проміжку $y^{*}<y_{0} \leq y_{2}$. Якщо при інтегруванні системи (2.7) використати перший інтеграл (2.6), то систему можна звести до системи 2-го порядку для функцій $y(\tau), \varphi(\tau)$, а третю функцію $\theta(\tau)$ отримувати з інтеграла (2.6) за формулою:

$$
\theta=\arcsin \sqrt{\frac{\Phi\left(y_{0}\right)}{\Phi(y)}}, \quad y_{1} \leq y \leq y_{2} .
$$

Це суттєво скорочує час обчислень, особливо на значних проміжках $\tau$ порядку $20 \pi$ і більше. 
Оскільки просторову картину траєкторій руху на торах складно аналізувати з точки зору резонансів за координатами, побудуємо геометричну модель для аналізу відхилень руху на торах від періодичного руху по центральному колу.

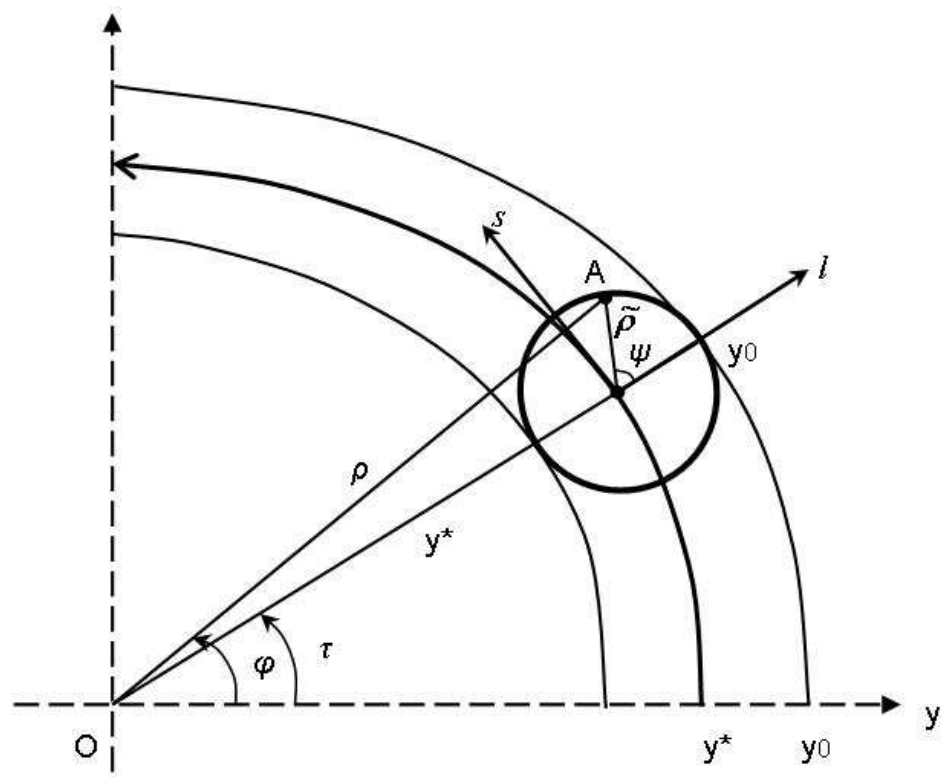

Рис. 2. Відхилення у проекції на горизонтальну площину

Для аналізу меридіонального руху точок на торах побудуємо відхилення рухомої точки $A$ від центра $O^{*}$ у меридіональній площині $(y, \theta)$, які подамо у місцевій полярній системі координат $(R, \beta)$ (рис.1). 3 геометричних відношень отримуємо:

$$
\begin{aligned}
& R=\sqrt{y^{2}+y *^{2}-2 y y^{*} \sin \theta} \\
& R \sin \beta=y \cos \theta, \quad \beta=\arcsin \left(\frac{y \cos \theta}{R}\right) \\
& R \cos \beta=y \sin \theta-y^{*} .
\end{aligned}
$$

Розглянемо також рух на торах у проекції на горизонтальну площину, віднесену до полярних координат $(\rho, \varphi)$, де

$$
\rho=y \sin \theta
$$

Введемо рухому систему координат $(l, s)$, зв'язану з рухом точки $O^{*}$ по центральному колу тора (рис. 2). Координатами точки $O^{*} \in\left(\rho^{*}, \varphi^{*}\right)$, де $\rho^{*}=$ $y^{*}, \varphi^{*}=\omega^{*} t=\tau$; місцеві полярні координати рухомої точки А позначено через $(\tilde{\rho}, \psi) .3$ геометричних співвідношень маємо (рис. 2$)$ :

$$
\begin{aligned}
& \tilde{\rho}=\sqrt{\rho *^{2}+\rho^{2}-2 \rho \rho * \cos (\varphi-\tau)} \\
& \rho \sin (\varphi-\tau)=\tilde{\rho} \sin \psi
\end{aligned}
$$


а відхилення $(l, s)$ дорівнюють

$$
\begin{aligned}
& l=\tilde{\rho} \cos \psi=\rho \cos (\varphi-\tau)-\rho * ; \\
& s=\tilde{\rho} \sin \psi=\rho \sin (\varphi-\tau) .
\end{aligned}
$$

Остаточно з урахуванням (2.10) виразимо відхилення через шукані функції системи рівнянь (2.7)

$$
\begin{aligned}
& l=y \sin \theta \cos (\varphi-\tau)-\rho * ; \\
& s=y \sin \theta \sin (\varphi-\tau) .
\end{aligned}
$$

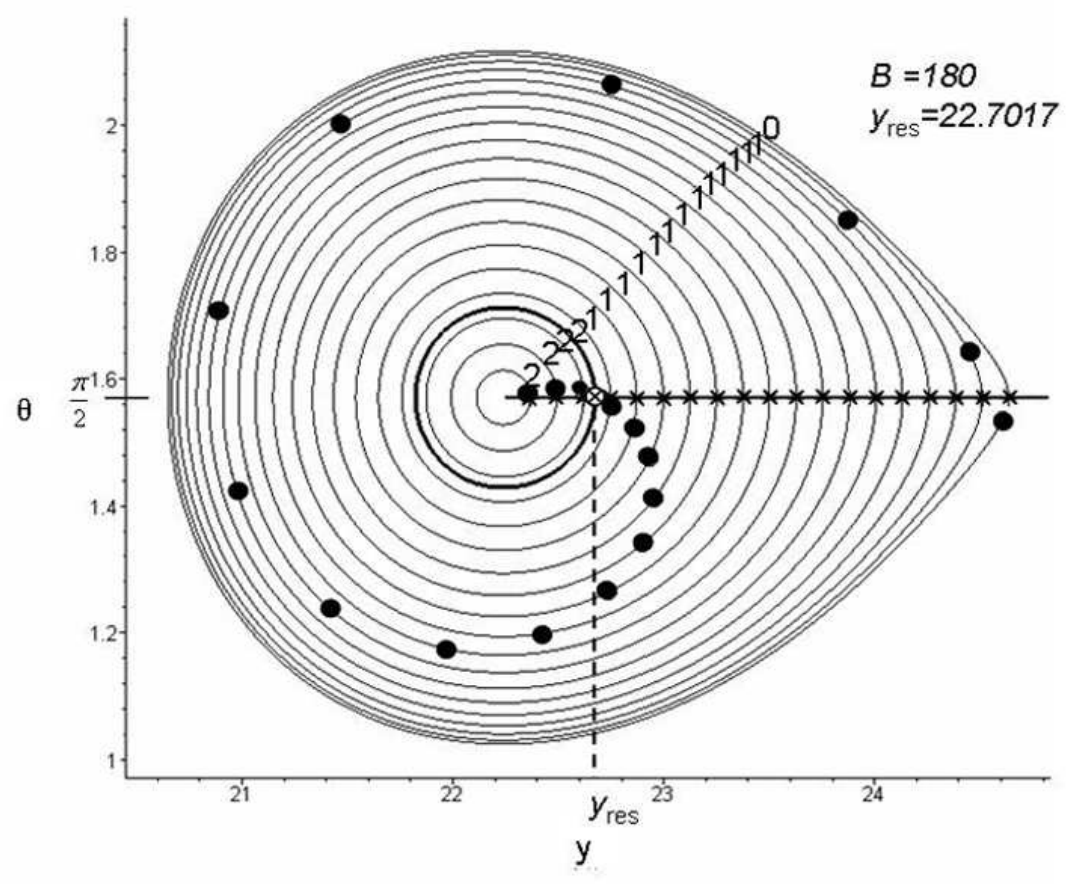

Рис. 3. Проекції траєкторій на меридіональну площину

Отримуючи при інтегруванні таблицю числових значень функцій $y(\tau)$, $\theta(\tau), \varphi(\tau)$, ми будуємо функції-відхилення $(l, s)$ та $(R, \beta)$ і фіксуємо кінцеві положення точок у горизонтальній та меридіональній площинах при $\tau$ $=2 \pi n$ для різних початкових значень радіуса $y_{0}$. Побудовані таким чином лінії-проекції траєкторій на меридіональну площину для 3-го тора структури $(2,11)$ зображено на рисунку 3 . Відрізок $\left[y^{*}, y_{r e s}\right]$ розбито на 20 частин, із точок поділу $y_{0}$ як початкових будувалися траєкторії на проміжку $0 \leq \tau \leq 4 \pi$ (два оберти), - усі вони й лежать на замкнутих лініях, що є напрямними лініями осесиметричних торів. На цих лініях цифрами 2 і 1 вказано число повних обертів зображальної точки, а маркерами позначено їх положення при $\tau=4 \pi$. Для резонансного радіуса $y_{\text {res }}$ положення початкової й кінцевої точок співпадають; відповідний тип резонансу та його параметри занесено до таблиці 2. У цілому видно, що меридіональне обертання на внутрішніх торах 
є більш інтенсивним, ніж на зовнішніх: на центральних чотирьох торах частинки здійснюють близько двох обертів (на резонансному торі рівно 2), а по зовнішніх торах - 1 повний оберт плюс дугу до кінцевої точки. I лише по крайньому тору рухома частинка трохи не досягає 1 оберту (рис. 3). У таблиці 2 наведено параметри резонансних співвідношень, віднайдених чисельним інтегруванням і аналізом законів руху за всіма трьома змінними для трьох тороїдних вихорів порядків 3,4 і 9. Значення параметра $B^{*}$ відповідають формулі (2.8) і мають мітку ${ }^{*}$, інші значення цього параметра підбиралися чисельним аналізом з умов резонансу.

Таблиця 2. Параметри резонансних співвідношень

\begin{tabular}{|c|l|c|c|c|c|c|c|}
\hline № вихору & $\begin{array}{l}\text { Резон. } \\
\text { радіус }\end{array}$ & \multicolumn{2}{|l|}{$\begin{array}{l}\text { Число } \\
\text { обертів }\end{array}$} & \multicolumn{3}{|c|}{ Похибка } & В \\
\hline & & $\mathrm{n} \tau$ & $\mathrm{n} \beta$ & $\mathrm{n} \varphi$ & $\Delta \beta$ & $\Delta \varphi$ & \\
\hline 3 -й & 24.37346 & 2 & 1 & 2 & 0,0006 & 0.0062 & 148.4 \\
$22.242096 \leq y_{0} \leq$ & 22.70173 & 2 & 2 & 3 & 0.0001 & 0.0981 & 180 \\
$\leq 24.761678$ & 24.37446 & 3 & 1 & 2 & 0.0007 & 0.0122 & 99 \\
& 24.37336 & 7 & 3 & 6 & 0.002 & 0.0188 & 127,2 \\
& 22.54925 & 3 & 2 & 3 & 0.0003 & 0.0011 & $118.5^{*}$ \\
\hline 4 -й & 29.74295 & 2 & 1 & 2 & 0.0004 & 0.05 & 137 \\
$28.623985 \leq y_{0} \leq$ & 30.81311 & 3 & 1 & 3 & 0.0001 & 0.06 & 154 \\
$\leq 30.965688$ & 30.80961 & 7 & 2 & 6 & 0.0008 & -0.024 & $131.4^{*}$ \\
\hline $9-$ й & 61.22809 & 4 & 1 & 5 & 0.0001 & -0.0351 & 187 \\
$60.590864 \leq y_{0} \leq$ & 61.68505 & 8 & 2 & 13 & 0.0014 & -0.0531 & 246 \\
$\leq 61.870495$ & 61.23618 & 10 & 2 & 10 & 0.0007 & 0.0886 & 150 \\
\hline
\end{tabular}

3 таблиці 2 випливає, що при значеннях параметра $B^{*}$ з $(2.8)$ та для торів малих порядків резонанси характеризуються синхронністю колового руху, тобто однаковим числом обертів по центральному колу та по торах.

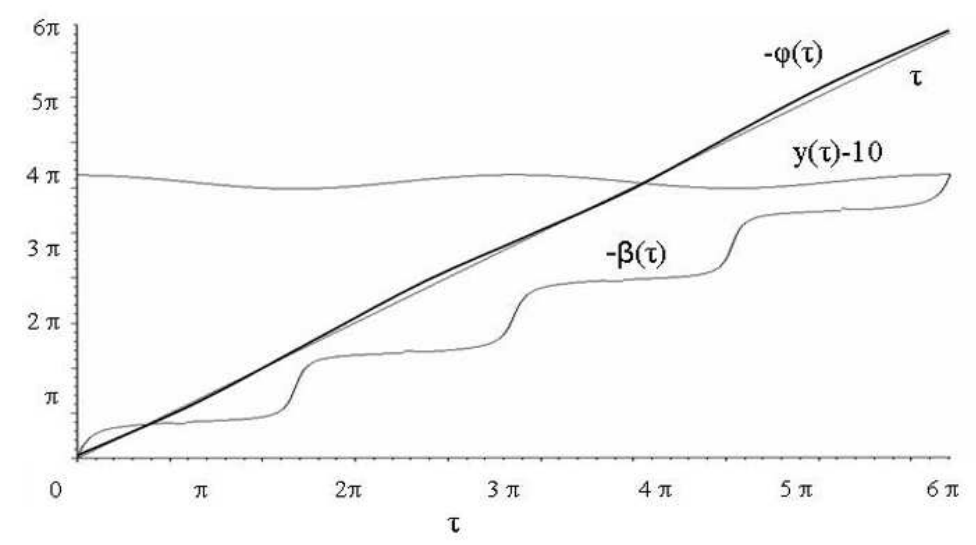

Рис. 4. Закон руху частинок на резонансному торі $\mathrm{B}=118,5466^{*}, \alpha=-0,00655, y_{0}=22.54925431$ 
У меридіональній площині обертання є повільнішим у 1,$5 ; 2 ; 5$ разів від колового обертання. Слід відзначити, що для торів високого порядку дуже важко знайти прості резонансні співвідношення на невеликих періодах3'являються співвідношення типу $(10: 2: 10),(4: 1: 5)$ та ін.

На рисунку 4 подано графіки законів руху частинок течії за координатами $y(\tau), \beta(\tau), \varphi(\tau)$ на проміжку $0 \leq \tau \leq 6 \pi$. Як бачимо, коливання за координатами $y$ та $\beta$ є синхронними, а відхилення колової координати $\varphi$ рухомої точки від рівномірного обертання центра $O^{*}$ - досить незначними. Результати аналізу відхилень $(l, s)$ проекцій на горизонтальну площину руху на торах від рівномірного колового руху центра тора подано на рисунку 5. Побудова відповідної резонансної траєкторії зроблена для 3-го тора з резонансним радіусом $y_{\text {res }}=22.54925431$. Як бачимо, ця траєкторія $є$ близькою до еліпса 3 відношенням півосей близько 3:1. Якщо цей результат поєднати з висновками роботи [2] про стягування силою Архімеда мас з околу до горизонтальної площини Лапласа, то ці обидва чинники могли б спричинити утворення супутника планети на резонансній еліптичній орбіті.

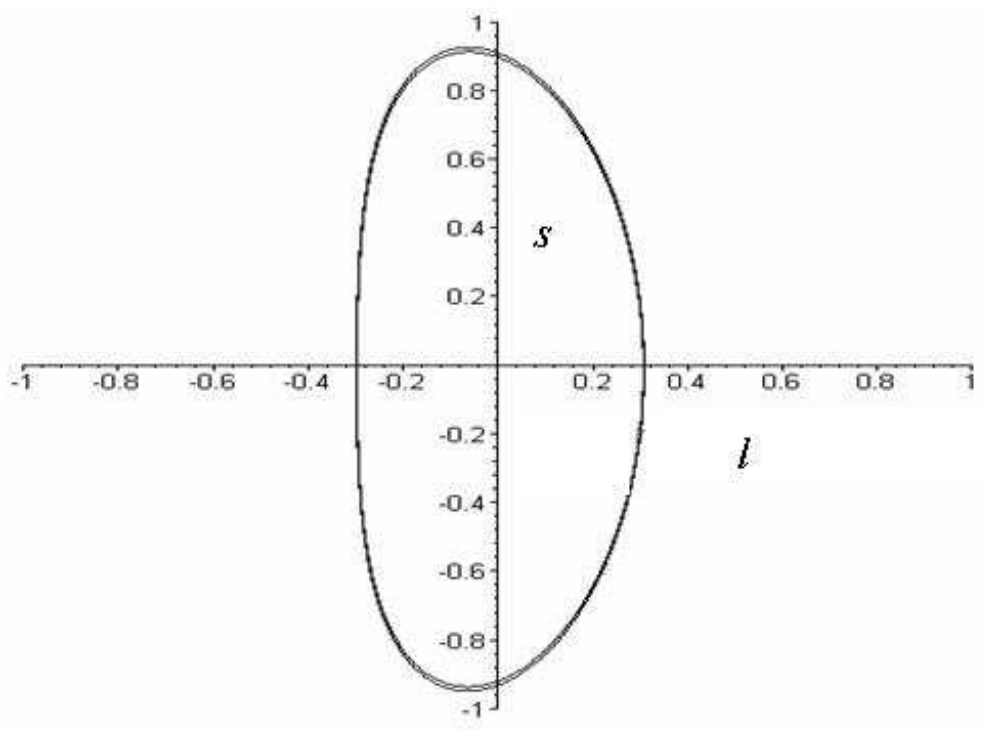

Рис. 5. Відхилення у проекції на горизонтальну площину $B=118,5466^{*}, \alpha=-0,00655, y_{0}=$ 22.54925431, $(l(0)=0,307, s(0)=0, l(6 \pi)=0,307, s(6 \pi)=-0,032)$

\section{3. Висновки}

3 точки зору подальшої еволюції описаного вище первинного руху вихору, коли центр тора втягував маси і ставав тяжіючою планетою, а деякі зовнішні маси якимось чином формувалися у її супутники, описана картина повинна була кардинально змінитися. Бо за законами Кеплера тяжіюча планета перебуває в одному з фокусів еліпса, а не у його центрі. Тому задачу про дослідження такої еволюції треба ставити додатково і за наявності градієнтного [2] та гравітаційного силових полів. Тут же ми показали, що у вихровій 
течї̈ планетарного вихору у кожному торовому кільці є резонансні тори, на яких траєкторії частинок замикаються.

\section{Бібліографічні посилання}

1. Перехрест B. I. Новий розв'язок гідродинамічних рівнянь Ейлера для сферичних вихрових течій // В. І. Перехрест, Р. В. Іванов // Вісник Дніпропетр. ун-ту, Механіка, вип. 6, т. 1, 2002.- С. 60-64. Математика, 2009. - Т. 18, № 2. - С. 62 -75 .

2. Перехрест В. I. Планетарний вихор та гіпотези Лапласа і Вайцзекера.// Вісник Дніпропетр. ун-ту, Механіка, вип. 13, т. 2, 2009 - С. 113-124.

3. Перехрест B. I. Про структури планетарних вихорів і закономірності їх обертання // В. I. Перехрест, М. М. Осипчук // Вісник Дніпропетр. ун-ту, Механіка, вип. 14, т.1, 2010.

4. Милн-Томпсон. Теоретическая гидродинамика.-М., 1964, - 655 с.

5. Von Weizsacker C.F.Z. Astrophys. 22, 1944, - p. $319-355$.

6. Альфвен $X$. Структура и эволюционная история Солнечной системы / Х. Альфвен, Г. Аррениус - К. : Наукова думка, 1981. - 332 с.

7. Чечельницкий A. М. Экстремальность, устойчивость, резонансность в астродинамике и космонавтике. М. : Машиностроение, 1980.

8. Молчанов A. M. О резонансной структуре Солнечной системы // Современные проблемы небесной механики и астродинамики, М. : Наука, 1973 - С. 32-42.

9. Molchanov A. M. The Reality of Resonances in the Solar Systems. ICARUS, v. 11, 1969.- p. $104-110$. 